\title{
Intelligent management system based on RFID+GSM
}

\author{
Jianing Zhang ${ }^{1, \mathrm{a}}$, Hao Chen ${ }^{2, \mathrm{~b}}$ and Shan Tang ${ }^{*}, 1,3, \mathrm{c}$
}

1. The School of Mechanical \& Electrical Engineering, Xuzhou Institute of Technology, Xuzhou 221000, China;

2 .Organization Department ,Xuzhou Institute of Technology,Xuzhou 221000, China;

3. Xu zhou Construction Vehicles Appearance and Function Design Engineering Technology

Research Center, Xu zhou 221000, China;

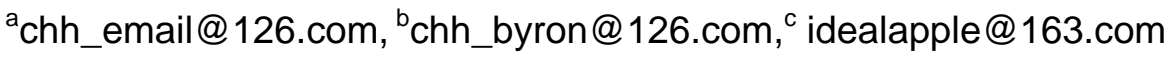

Corresponding Author: Shan Tang

Keywords: Internet,RFID technology,GSM system,intelligent management

\begin{abstract}
Internet of things technology application and promotion, RFID has been further developed as core technology. Through the positive research and innovation of schools, enterprises and government departments, the actual application of RFID technology has been developing rapidly. The purpose of this paper is to design an intelligent management system based on RFID technology, and text messages through the GSM system. In the rapid development of the information age, many enterprises more and more attention to investment and application of management information system and information management tools have been shaped from manual management to computer - aided management and computer management pattern. Based on the student attendance RFID application system is intelligent complete examining students' attendance. The real-time automatic collection of data information, automatically analyze the collected data, and then report to visual interface, and use the GSM SMS notification system.

In recent years, with the continuous development of the Internet of things technology application and promotion of RFID technology by the colleges and universities, government, competing research companies and other enterprises, which have made great progress in many fields. And the results are applied to agriculture, industrial, medical, military and various aspects of the third industry. In order to improve the level of national life, strengthen the maintenance of information security, and promote the process of informatization in china. Our country has already formed a complete industrial system of things, part of the field has formed a certain size of the market, and formed a complete industrial chain of low-frequency and high-frequency RFID and in Beijing, Shanghai, Guangdong based spatial layout, to 2009 market size reached 85 billion yuan and become the world's third largest market.
\end{abstract}

\section{The overall design scheme of the system}

This system is mainly to do so with tape contains RFID chip student card students in through the door of the classroom without contact punch machine can automatically induction attendance, and in many people at the same time through the teaching building front door do achieve attendance and do not need to queue up, and the control of reader to receive to upload the information to the computer terminal processing, accurate records of students traveling time and other information. The list of students were absent through the GSM system in the form of text messages sent to the relevant person in charge. The general block diagram shown in figure 1.

The main function is to receive the student card reader information and upload to the server so that the server receives the total, the total information in order to terminal equipment system statistics.

The framework of the reader as shown in figure 3 : 


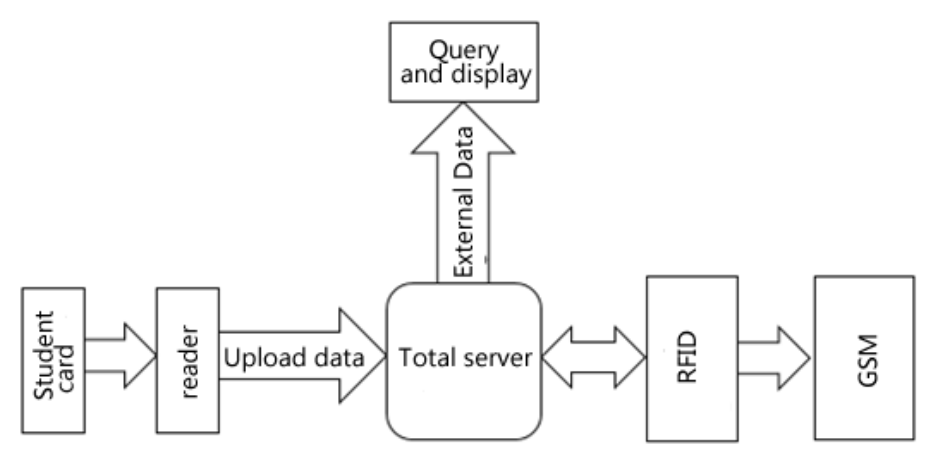

Fig. 1 classroom attendance system

\section{2. system hardware design}

\section{1 student card}

The RFID chip is the use of CY-14443A Series RF read-write module, this module card reader chip based on ISO14443 standard. The application of access control and system identification is particularly applicable to the ISO14443 standard.

In the specific time set for automatic card. And CY-14443A series which we used in this system has a built-in antenna, if necessary, can be an external antenna. The built-in antenna can improve the degree of integration can be read within a specific range of student card, also in the same circuit can also to connect an external antenna, improve the reusability of the system, which reduces production cost. In addition, a read head of a built-in antenna can also as a source antenna is used.

Student card making use of RFID tags, each card is internally provided with a corresponding students department, class, name, student number and other campus personal information. When the student cards are in the reading range of the card reader, the reader will read the information uploaded to the master server. The structure is shown in figure 2.

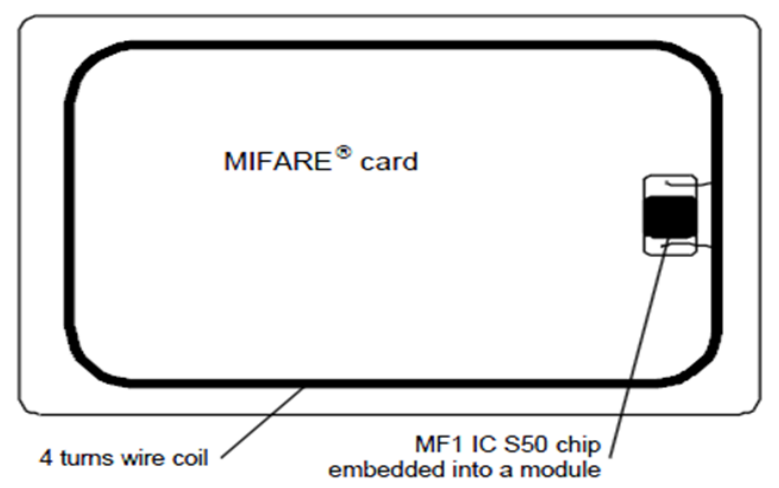

Fig. 2 Schematic diagram of student card

\section{2 reader}

The main function is to receive the student card reader information and upload to the server so that the server receives the total, the total information in order to terminal equipment system statistics.

The framework of the reader is shown in figure 3:

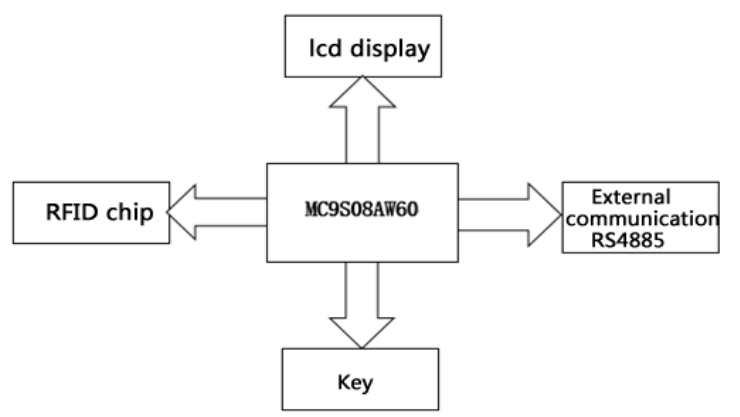

Fig. 3 Diagram of the reader 


\subsection{MC9S08AW60}

Reader hardware system with MCU as the core, using Freescale mc9s08aw60 chip, the chip is low cost, high performance 8-bit microprocessor unit (MCUs) hcs08 family members using the enhanced hcs08 core. It has a quad flat package 64/48/44 pin (QFP).

The application characteristic of MC9S08AW60 is very rich. It uses 8 bit HCS08 central processing unit (CPU). CPU frequency $40 \mathrm{MHz}$, internal bus frequency is $20 \mathrm{MHz}$, with $\mathrm{HC} 08$ subset of instructions, increase the BGND instruction, the interface with single background debug mode, allows a single breakpoint debugging online, with on-chip real-time function, support up to 32 interrupt / reset source. The chip also has up to $60 \mathrm{~KB}$ chip online programmable FLASH memory, with block protection and security options, and up to $2 \mathrm{~KB}$ in RAM. Clock source options include crystal, resonator, external clock, or internally generated clock and NVM precision cutting edge. System protection mode can be used optional computer is operating correctly reset (COP), low voltage detection and reset or interrupt, illegal operation code detection and reset and address illegal detection and reset (some of the equipment does not have the illegal address). External device with up to 16 channels of ADC module, has 10 bit AD converter and automatic comparison function; two serial communication interface module and optional 13 interrupt; serial peripheral interface module; operation up to $100 \mathrm{kbps}$ to the maximum bus load in integrated circuit interconnect bus module; a 2 channel and a 6 channel 16 bit timer / pulse width modulator module (TPM); up to 8 pin of the keyboard interrupt module. The input and output up to 54 general-purpose I/O pins, and master reset pin and a power on reset and internal pull reset pin etc.. The power saving mode including Wait and STOPS two models.

\section{4 external communication}

External communications using MAX485 interface chip. Maxim company a RS-485 chip MAX485 interface chip, the power of a single $+5 \mathrm{~V}$, rated current is $300 \mu \mathrm{A}$, the half-duplex communication mode. It will achieve a function which will convert TTL level to RS-485.

It can be seen from the figure, MAX485 chip pin is very simple, a driver and receiver with internal. RO and DI are the input of the receiver output and driver, connected with the MCU only with MCU RXD and TXD can be linked to; RE and DE were received and sent to end, when /RE is a logic 0 , the device is in the receiving state; When DE is a logic 1 , the device is in this state, because the MAX485 working in half duplex state, so only one pin of the SCM control of the two pin; The $A$ and $B$ ends respectively for sending and receiving the differential signal terminal, when the level of the A pin is higher than $B$, on behalf of the transmitted data is 1 ; otherwise 0 . In connection with single chip wiring is very simple, only need a control signal receiving and sending to MAX485. At the same time, will increase the resistance between the A and B which generally is $100 \Omega$. Microcontroller and external host through RS485 interface chip connection diagram is shown in figure 4.

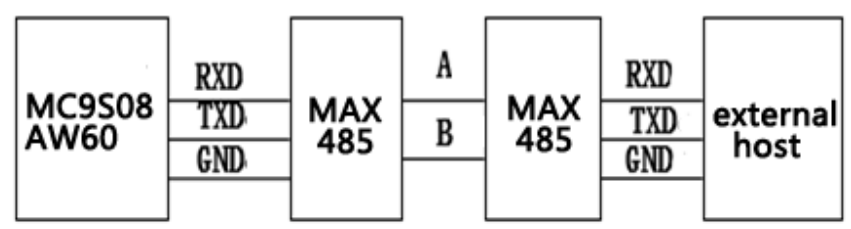

Fig. 4 Connection diagram of microcontroller and external communication

\section{Software design}

The central control software system is the center of class attendance system, RFID card reader and to control the working state of students from the classroom and statistical data processing etc.. Main features: easy operation and control; through the serial communication protocol, to achieve the reader control and data transmission; student information entry is simple and convenient, maintain confidentiality and good; fast statistical data processing; perfect information query function. 
System software function modules include: user login module, real-time report and retreat display module, reader control module, database management module, data processing module. As shown in figure 5 :

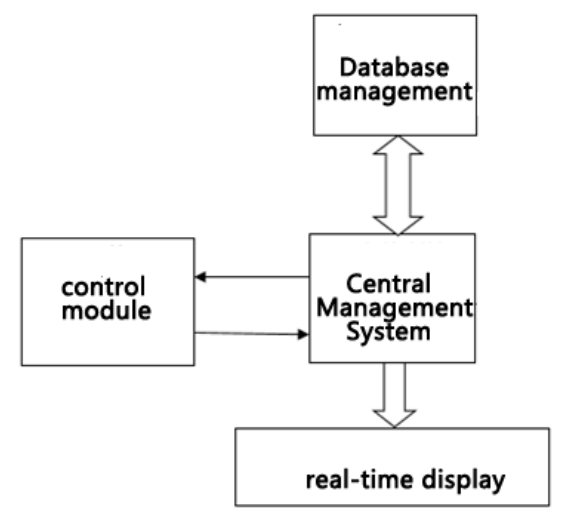

Fig. 5 The module of software system

\section{Conclusion}

In this paper, we mainly study smart classroom attendance system, the characteristics of the application of RFID technology to achieve student classroom report and leave record automation and intelligent management, can also use GSM SMS notification is another highlight of this paper. At the same time, RFID technology in recent years, various industries and fields have been studied, using the maximum range of the related hardware facilities have also been large-scale commercial production. Therefore, from the selection of raw materials and the greatly strengthened the feasibility and operability of the system, the system has a wide range of application feasibility. I believe that with the continuous development of the Internet of things application technology, RFID technology continues to mature, the system will be improved and widely used.

\section{REFERENCES}

[1] Ngai E W T, Moon K K L, Riggins F J, et al. RFID research: An academic literature review (1995-2005) and future research directions[J]. International Journal of Production Economics, 2008, 112(2):510-520.

[2] Wu N C, Nystrom M A, Lin T R, et al. Challenges to global RFID adoption[J]. Technovation, 2006, 26(12):1317-1323.

[3] Han S, Lim H S, Lee J. An Efficient Localization Scheme for a Differential-Driving Mobile Robot Based on RFID System[J]. IEEE Transactions on Industrial Electronics, 2007, 54(6):3362-3369.

[4] Angeles R. RFID Technologies: Supply-Chain Applications and Implementations Issues[J]. IEEE Engineering Management Review, 2007, 35(2):64-64.

[5] Subramanian V, Fréchet J M J, Chang P C, et al. Progress Toward Development of All-Printed RFID Tags: Materials, Processes, and Devices[J]. Proceedings of the IEEE, 2005, 93(7):1330-1338.

[6] Lu M T, Lin S W, Tzeng G H. Improving RFID adoption in Taiwan's healthcare industry based on a DEMATEL technique with a hybrid MCDM model[J]. Decision Support Systems, 2013, 56:259-269.

[7] Azevedo S G, Carvalho H, Cruz-Machado V A. RFID application infant security systems of healthcare organizations[J]. Acm Transactions on Modeling \& Computer Simulation, 2014, 281(3):1059-1073.

[8] Hye Sun K, Man-Jeong P, Yeon Ju K, et al. Effects of Whole-Body Exposure to 915 MHz RFID on Secretory Functions of the Thyroid System in Rats[J]. Bioelectromagnetics, 2013, 34(7):521-529. 